\title{
O ENSINO DE RELACIONAMENTO TERAPÊUTICO EM ENFERMAGEM PSIQUIÁTRICA
}

\author{
Evalda Cançado Arantes *
}

O ensino de enfermagem psiquiátrica tem se constituído em tarefa árdua em decorrência da dificuldade de mensuração das ações da enfermeira, no campo da psiquiatria. Ao iniciar nossas atividades como docente tínhamos grande preocupação em ensinar aos estudantes prover aos pacientes cuidados básicos para a manutenção da vida, higiene pessoal, além de vigilância e distração constantes para evitar que os mesmos apresentassem comportamento destrutivo. Como resultado, desse tipo de ênfase dada ao ensino, acreditamos que a maioria de nossos estudantes terminavam o curso com a. idéia de que a enfermeira nada mais tinha a realizar, no campo da enfermagem psiquiátrica, além de atividades recreativas.

A incorporação de novos conhecimentos e aquisição de novas experiências levou-nos à reformulação completa de objetivos e modo de ação. Como consequência, houve uma modificação radical no ensino de enfermagem psiquiátrica ministrado aos nossos estudantes, do Curso de Graduação em Enfermagem. Foi a partir de então que o ensino passou a ter como base o relacionamento terapêutico entre estudante e paciente.

Após a introdução do ensino de relacionamento terapêutico, há sete anos, fizemos várias reformulações nas orientaçōes dadas aos estudantes e na forma de ensinar. Quatorze grupos de estudantes do Curso de Graduação em Enfermagem já experimentaram as várias formas por nós adotadas e esperamos que nossa experiência possa ser útil a outros docentes de enfermagem.

O ensino do relacionamento terapêutico é iniciado na primeira semana do curso para que o estudante seja alertado sobre a importância do seu trabalho junto aos pacientes, e tem uma sequência pré-estabelecida:

* Professora da Disciplina Enfermagem Psiquiátrica da Escola de Enfermagem da USP. 
- orientação sobre a abordagem inicial dos pacientes; pacientes;

- leitura da literatura existente sobre relacionamento com

- apresentação de resumos das leituras e discussão final sobre: conceito, fases, fenômenos, dificuldades e requisitos básicos para o relacionamento terapêutico.

$\mathrm{Na}$ segunda semana cada estudante inicia o relacionamento formal com um paciente por ele escolhido e do qual fez observação de comportamento na semana anterior. Este paciente escolhido deverá ser seguido até o final do curso, que tem a duração de oito semanas. Para esta fase do estudo os estudantes recebem orientação sobre a forma do diário, a ser seguida, a avaliação de suas interações diárias e a análise da evolução semanal de seus relacionamentos com seus respectivos pacientes. O trabalho passa a ser individual e sob supervisão direta de uma das docentes. Os problemas encontrados são resolvidos individualmente, sob orientação da docente, ou com o auxílio da classe quando o assunto é de interesse geral.

Semanalmente, os estudantes entregam todo o material, por escrito, para que as docentes se inteirem da direção tomada por eles e possam orientá-los, individualmente, durante a entrevista formal de supervisão do relacionamento.

Numa etapa posterior é feita a orientação sobre o estudo de relacionamento, trabalho final do curso, que envolve coleta de dados sobre o paciente, dentro e fora do hospital.

Com a finalidade de facilitar o trabalho de estudantes e docentes são fornecidas, aos alunos, orientações escritas de todas as etapas do estudo e aplicação do relacionamento terapêutico. A ordem das orientações é a que segue:

1. Leitura obrigatória.

Para facilitar o estudo dos alunos, a classe é dividida em grupos pequenos que fazem a leitura de trechos por nós selecionados e apresentam os resumos para discussão.

2. Diário.

Cada estudante mantém uma anotação diária de entrevista formal com seu paciente. Os propósitos dessa anotação são os de fornecer ao estudante elementos para reflexão e de mostrar ao professol os pontos em que o mesmo precisa ser orientado.

O diário tem uma parte introdutória da qual fazem parte dados pessoais sobre o paciente e uma observação inicial do comportamento do mesmo. 
Sua forma é estabelecida por nós de modo a ressaltar os dados de maior relevância tanto para o estudante como para a docente que irá fazer sua orientação. A forma adotada por nós é composta de três partes: folha inicial, folha(s) de continuação e folha de avaliação.

\section{Folha inicial}

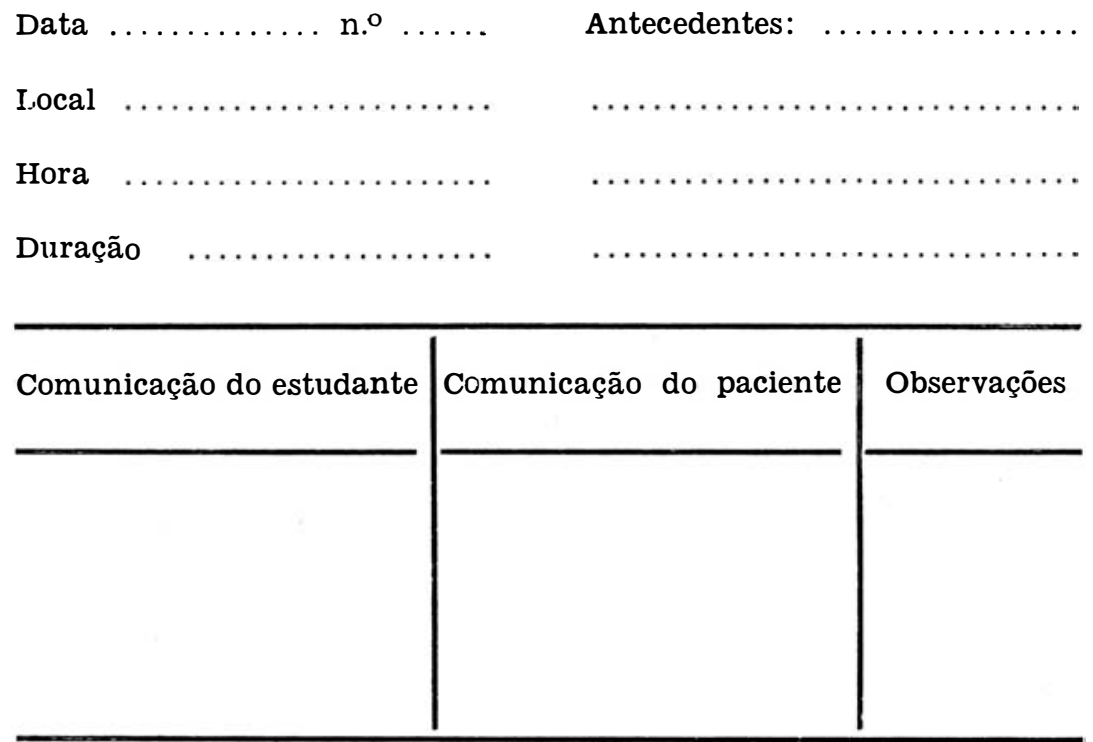

Folha de avaliação

1. Avaliação da presente interação

2. Objetivos

3. Planos para próxima interação 
Os estudantes recebem orientação sobre o que deve ser escrito em cada parte do diário:

\section{Antecedentes.}

Nesta parte devem ser colocados todos os eventos pertinentes que tenham antecedido a entrevista formal:

a) incidentes ocorridos, no dia anterior ou durante as primeiras horas da manhã, que possam influenciar o relacionamento no presente dia;

b) comportamento do paciente durante as horas que precedem a entrevista;

c) descrição do ambiente em que se deu a entrevista e,

d) as condições emocionais do paciente e do estudante ao ter início a mesma.

Comunicações do paciente.

a) Reprodução das comunicações, verbal e não verbal do paciente.

b) Descrição de mudanças de comportamento do paciente percebidas durante a interação.

Comunicações do estudante.

a) Reprodução da comunicação verbal havida e da não verba] que tenha percebido.

b) Descrição de suas próprias mudanças de comportamento durante a entrevista.

Observações.

a) Sentimentos de ambos que tenham sido percebidos durante a entrevista.

b) Comentários sobre as situaçōes surgidas e que são feitos anós a reprodução do diálogo.

c) Observações e indagaçōes feitas pela docente ao verificar o diário.

Avaliação do relacionamento.

1. Avaliação da presente interação.

A interação de cada dia deve ser avaliada, no seu todo, com a utilização do método de solução de problemas considerando: 
a) a comunicação que foi planejada para essa interação e se com a execução do plano conseguiu atingir os objetivos propostos;

b) os efeitos do meio ambiente no comportamento do paciente, as interpretações possíveis de seu comportamento e a identificação de suas necessidades;

c) os problemas do paciente que foram definidos;

d) os problemas do estudante que surgiram, na presente situação, a identificação de seus próprios sentimentos e preconceitos e a influência que os mesmos possam ter tido na situação descrita;

e) a interação presente situada dentro do processo de relacionamento e identificação dos fenômenos que estão ocorrendo no momento.

2. Objetivos.

Determinar o que precisa ser modificado no comportamento do paciente e no do estudante.

3. Plano para a próxima interação.

Destacar as técnicas de comunicação e as atividades que foram planejadas para modificar o comportamento do paciente.

4. Evolução semanal do relacionamento.

Resumo semanal com a finalidade de levar o estudante a refletir e a procurar dirigir o relacionamento para um objetivo terapêutico. O esquema seguinte é fornecido para facilitar a redação.

\section{A - Ocorrências}

Comportamento do paciente em relação ao estudante, médico, pessoal de enfermagem, familiares, outras pessoas ou situaçōes dentro do hospital.

\section{B - Avaliação.}

Acontecimentos em geral que podem ter determinado aqueles comportamentos.

Problemas sentidos pelo paciente.

Problemas do paciente identificados pelo estudante.

Dificuldades sentidas pelo estudante no seu relacionamento com o paciente e com as demais pessoas no hospital.

Fase atual do processo de relacionamento com o paciente, feiômenos esperados e fenômenos que ocorreram. Justificar sua afirmações com passagens registradas no seu "diário". 
C - Conduta.

Como participar do plano terapêutico determinado para o paciente.

Meios e técnicas de comunicação mais indicados para a presente fase de relacionamento.

Medidas terapêuticas de relacionamento e atividades que devem ser desenvolvidas junto ao paciente.

5. Orientação para o estudo de relacionamento.

Este trabalho é o que tem maior peso na avaliação do curso; é individual e consequente de cuidados que o estudante prestou a um paciente durante seis semanas, no mínimo.

1. Identificação do paciente.

1.1. Nome, idade, estado civil, grau de instrução. Procedência, residência, profissão e ocupação. Condições sócio-econômicas, situação do paciente dentro da família e da comunidade. Assistência recebida da família antes e depois da doença.

1.2. Hábitos pessoais antes e depois da internação: sono, alimentação, higiene pessoal, eliminações, atividades e recreação.

1.3. Comportamento do paciente que acarretou a internação. Quem decidiu trazê-lo ao hospital.

1.4. Comportamento do paciente dentro do hospital, e suas condições físicas e mentais até o início do estudo.

1.5. Diagnóstico médico e sintomas que o justificaram.

1.6. Tratamentos a que foi submetido em internações anteriores.

2. Relacionamento.

Relato minucioso da evolução de seu relacionamento com o yaciente e justificativa de todas as afirmações com fatos registrados no "diário".

2.1. Razões da escolha do paciente para estudo e identificação dos sentimentos provocados no estudante pelo paciente.

2.2. Relacionamento inicial (abordagem do paciente). 
2.3. Evolução do relacionamento (fases e características):
a) comportamentos do paciente que você se propôs mo- dificar;
b) técnicas ou medidas terapêuticas de relacionamento utilizadas por você, para conseguir as modificaçōes propostas;
c) modificações percebidas no comportamento do paci- ente;
d) medidas utilizadas que julga terem sido responsáveis pelas modificações ocorridas;
e) fatores alheios a sua pessoa, que podem ou devem ter contribuído para aquelas modificaçōes no comporta- mento do paciente;
f) modificações ocorridas no seu próprio comportamento, frente ao seu paciente;
g) dificuldades sentidas no relacionamento com o seu paciente;
h) relato dos fenômenos de relacionamento ocorridos, de acordo com a sequência dos mesmos. durante todo o período de estudo, mesmo que haja repetições de fe- nômenos.

2.4. Necessidades do paciente que foram percebidas.

2.5. Fase atual do relacionamento.

2.6. Preparo feito para o término do relacionamento.

2.7. Descrição do relacionamento atual do paciente com enfermeira, médico, pessoal do hospital, demais pacientes, parentes e amigos.

2.8. Avaliação final do relacionamento.

3. Plano de Assistência de Enfermagem.

Citação de problemas, soluções propostas, avaliações e objetivos traçados durante todo o período de estágio.

Descrição dos tratamentos psiquátricos recebidos nesta internação e dos resultados dos mesmos e apenas citação dos demais tratamentos.

4. Bibliografia e fontes de consulta.

A eficiência do ensino é medida pelo desempenho dos estudantes no campo de prática e pela avaliação do trabalho de relacionamento. Até o momento podemos dizer que os resultados têm 
sido positivos, apesar das dificuldades encontradas tanto pelas docentes como pelos estudantes.

O número insuficiente de docentes tem sido nossa principal dificuldade. A aplicação de relacionamento terapêutico exige das docentes conhecimentos profundos além de um enorme investimento de tempo. Esta dificuldade torna-se maior em face do número crescente de estudantes o que faz do ensino uma tarefa penosa, considerando que o programa a ser desenvolvido tem outras unidades também importantes.

Os programas encontrados pelos estudantes não são menores que os das docentes. A primeira dificuldade que surge é o medo do desconhecido pois é a primeira vez que se aproximam de doentes mentais, com a obrigação de cuidar deles. A seguir sentem dificuldade em compreender a comunicação do paciente e como consequência resistem em aceitar o relacionamento como processo terapêutico, o que influi notadamente na avaliação do relacionamento ciário e no planejamento para relacionamentos futuros. Os estudantes sentem-se insatisfeitos porque julgam não estar sendo úteis aos pacientes e tenderiam a abandoná-los se a professora não interferisse no sentido de ajudá-los a avaliar suas próprias reações.

Os atendentes e auxiliares de enfermagem interferem no relacionamento dos estudantes com seus pacientes porque não compreendem a natureza do que eles chamam de "bate-papo" ou de "pajeação".

Os enfermeiros criticam o envolvimento dos estudantes com os seus respectivos pacientes e a falta de habilidade dos mesmos na aplicação de tratamentos como insulinoterapia e eletrochoque quanco, na realidade, essa falta de treino é decorrente do desuso em que tais tratamentos caíram. Ainda há prescrições desses tratamentos porém, em número cada vez mais reduzido e em contraposição ao número de estudantes que vem aumentando, consideravelmente, nos últimos anos.

Há também, de modo geral, censura ao fato do estudante se prender a um único paciente para estudo e não estar voltado para todos, principalmente no que se refere a solicitá-los para participar de atividades recreativas.

Apesar das dificuldades encontradas, do cansaço que este tipo de ensino provoca e das censuras recebidas, nós consideramos a experiência muito valiosa. Acreditamos na importância do relaciona- 
mento terapêutico, principalmente para formação básica de enfermeiros. Com o ensino que estamos ministrando esperamos alertá-los para sua responsabilidade como agente terapêutico e, ao mesmo tempo, dar-lhes condições para atingir um nível de desenvolvimento mais elevado no campo da enfermagem psiquiátrica.

\section{BIBLIOGRAFIA}

Altschul, A. Manual de enfermeria psiquiátrica. México, Continental, 1968. p. $275-88$.

BURD, S. F. \& MARSHALL, M. A. Some clinical approaches to psychiatric nursing. New York, Macmillan. 1963.

HAYS, J. S. \& LARSON, K. H. Interaracting with patients. New York, Macmillan, 1963.

HOFLING, C. K. et al. Enfermería psiquiátrica. 2. ed. México. interamericana, 1970. p. 23-60.

HOLMES, M. J. \& WERNER, J. A. Psychiatric nursing in a therapeutic community. New York. Macmillan, 1966.

MATHNEY, R. V. \& TOPALIS, M. Enfermeria psiquiátrica. 3. ed. MÉXICO, Interamericana, 1962. p. 67-75, 76-96.

MERENESS, D. \& KARNOSH, L. J. Elementos de enfermeriia psiquiátrica. México, Prensa Médica Mexicana, 1964. p. 45-55.

PEPLAU, H. E. Interpersonal relations in nursing. New York, G. P. Putnam's Sons, 1952.

PEPLAU, H. E. Princípios básicos para la orientación del paciente. W ashington, OPAS. 1968. p. 8-57.

TRAVELBEE, J. Intervention in phychiatric nursing: process in the oneto-one relationship. Philadelphia, F. A. Davis, 1969. 